\title{
Soft Tissue Tumors in Adults: ESSR-Approved Guidelines for Diagnostic Imaging
}

ARTICLE in SEMINARS IN MUSCULOSKELETAL RADIOLOGY • DECEMBER 2015

Impact Factor: 1.09 · DOI: 10.1055/s-0035-1569251

16 AUTHORS, INCLUDING:

Filip M Vanhoenacker

Algemeen ziekenhuis Sint-Maarten

377 PUBLICATIONS 3,198 CITATIONS

SEE PROFILE
Joan C Vilanova

Universitat de Girona

190 PUBLICATIONS 1,095 CITATIONS

SEE PROFILE 


\section{Soft Tissue Tumors in Adults: ESSR-Approved Guidelines for Diagnostic Imaging}

Iris M. Noebauer-Huhmann, MD ${ }^{6}$ Marc-André Weber, MSc ${ }^{1}$ Radhesh K. Lalam, MD

Siegfried Trattnig, MD ${ }^{6}$ Klaus Bohndorf, MD ${ }^{6}$ Filip Vanhoenacker, MD, PhD ${ }^{5}$ Alberto Tagliafico, MD ${ }^{2}$ Carla van Rijswijk, MD, PhD ${ }^{11}$ Joan C. Vilanova, MD, PhD ${ }^{4}$ P. Diana Afonso, MD ${ }^{13}$ Martin Breitenseher, MD ${ }^{14}$ lan Beggs, FRCP, FRCR ${ }^{12}$ Philip Robinson, MB ChB (Honours), MRCP, FRCR ${ }^{9,10}$ Milko C. de Jonge, MD BSc ${ }^{7,8}$ Christian Krestan, $\mathrm{MD}^{6}$ Johan L. Bloem, MD, $\mathrm{PhD}^{11}$

${ }^{1}$ Diagnostic and Interventional Radiology, University Hospital Heidelberg Im Neuenheimer Feld, Heidelberg, Germany

2 Department of Experimental Medicine -DIMES-, Institute of Anatomy, University of Genova, Genova, Italy

${ }^{3}$ Department of Radiology, Robert Jones and Agnes Hunt Orthopaedic Hospital, Oswestry, United Kingdom

${ }^{4}$ Clínica Girona, Institut Catalan of Health-IDI, University of Girona, Girona, Spain

${ }^{5}$ Department of Radiology, General Hospital Sint-Maarten, DuffelMechelen, Universities of Antwerp and Ghent, Duffel, Belgium

${ }^{6}$ Department of Biomedical Imaging and Image Guided Therapy, Medical University of Vienna, Austria

7 Department of Radiology, Zuwe Hofpoort Hospital, Woerden, the Netherlands

8 Department of Plastic, Reconstructive and Hand Surgery, Academic Medical Center, Amsterdam, the Netherlands

9 Leeds Teaching Hospitals Trust, Chapel Allerton Hospital, Leeds, United Kingdom

${ }^{10}$ Leeds Musculoskeletal Biomedical Research Unit, University of Leeds, Leeds, United Kingdom

${ }^{11}$ Department of Radiology, Leiden University Medical Center, the Netherlands

12 Department of Radiology, Royal Infirmary, Edinburgh, United Kingdom

${ }^{13}$ Hospital Beatriz Angelo, Lisbon, Portugal

${ }^{14}$ Orthopedic Surgery, Radiology, Landesklinikum Horn, Horn, Austria
Address for correspondence Iris M. Noebauer-Huhmann, MD, Department of Biomedical Imaging and Image Guided Therapy, Medical University of Vienna, Austria (e-mail: iris.noebauer@meduniwien.ac.at).

Semin Musculoskelet Radiol 2015;19:475-482.
Abstract
Keywords
- soft tissue tumor
- guidelines
- diagnostic algorithm
- imaging methods
- ESSR

Soft tissue sarcomas are rare, but early, accurate diagnosis with subsequent appropriate treatment is crucial for the clinical outcome. The ESSR guidelines are intended to help radiologists in their decision-making and support discussion among clinicians who deal with patients with suspected or proven soft tissue tumors. Potentially malignant lesions recognized by ultrasound should be referred for magnetic resonance imaging (MRI), which also serves as a preoperative local staging modality, with specific technical requirements and mandatory radiological report elements. Radiography may add information about matrix calcification and osseous involvement. Indeterminate lesions, or lesions in which therapy is dependent on histology results, should be biopsied. For biopsy, we strongly recommend referral to a specialist sarcoma center, where an interdisciplinary tumor group, with a specialized pathologist, radiologist, and the surgeon are involved. In sarcoma, a CT scan of the chest is mandatory. Additional
Issue Theme Advances in

Musculoskeletal Computed Tomography and Tumor Imaging; Guest Editor, Patrick Omoumi, MD, MSc, PhD ISSN 1089-7860. 
staging modalities are entity-specific. There are no evidence-based recommendations for routine follow-up in surgically treated sarcomas. However, we would recommend regular follow-up with intervals dependent on tumor grade, for 10 years after the initial diagnosis.

\section{Rationale and Objective of the ESSR Guidelines}

Soft tissue tumors are rare and represent a diverse group of heterogeneous entities. ${ }^{1}$ Sarcomas account for only $\sim 1 \%$ of soft tissue tumors in adults. ${ }^{2}$ Early accurate diagnosis and appropriate treatment are crucial for optimum outcome. ${ }^{3}$ Therefore, regularly updated guidelines for diagnostic strategy containing both minimal requirements and recommendations for optimization are required.

The European Society of Musculoskeletal Radiology (ESSR) guidelines are not meant to be prescriptive but are intended to help radiologists in their decision management and to support discussion among clinicians who deal with suspected or proven soft tissue tumors. We are aware that variations exist between countries and that the procedure varies in a minority of patients with special entities. We wish to stress the role of specialist sarcoma treatment centers, especially in cases of uncertainty and to avoid procedures when sarcomas become evident only during surgery, resulting in intralesional resection. We strongly recommend referral to a specialist sarcoma center for biopsy in indeterminate or likely malignant tumors.

\section{History and Clinical Features}

The following information should be available for the radiologist:

History: (a) Has there been a recent trauma (caveat: many patients report trauma that may be unrelated and misleading)? (b) Is the patient anticoagulated? (c) When did the patient first notice the lesion? Is it growing, and how fast? (d) Does it change in size (e.g., dependent on position, exercise, or muscle contraction/relaxation)? (e) Is there any oncologic history (malignancy, chemotherapy, or radiotherapy)? (f) Is there history of previous surgery?

A standardized checklist, primarily filled out by the patient, and discussed with the radiologist, is considered advisable.

Clinical symptoms and palpation: (a) Is the lesion painful? (b) Is it palpable, and if so, is it hard or soft? (c) Is it movable against the skin and underlying tissue? (d) Are there skin alterations or pathologic vessels? (e) Single or multiple lesions?

\section{Primary Imaging}

Patients with palpable lumps and suspected soft tissue tumor are numerous, resulting in a high initial workload, but imag- ing should be performed in most. Unless a lesion is clinically suspicious for malignancy ( $>5 \mathrm{~cm}$, deep, firm, and fixed on palpation), a reliable primary-triage image modality, in combination with clinical features, can be used to decide which patients need further work-up and who should be referred to a dedicated tumor center.

\section{Ultrasound}

In patients with a suspected soft tissue tumor, ultrasound (US) is considered the appropriate initial triage imaging modality as long as the tumor is accessible by US. ${ }^{4-6}$ The presence of a soft tissue tumor can be confirmed, but characterization is limited, and intra-articular and osseous involvement cannot be diagnosed reliably. US is readily available, "real time," radiation free, and cost effective but depends on the skill of the sonographer and may be challenging in obese patients. Reproducibility and reliability depend on appropriate documentation. Although US is excellent for the detection of even very small lesions, it may miss lesions in deep locations. Small areas of scar tissue can be misinterpreted as recurrence in patients who have had previous surgery.

\section{Technical Ultrasonography Standards}

Mandatory requirements: The US hardware should be quality assured, images stored in a picture archival communication system, and a written report available for each examination.

State-of-the-art scanners should be used, with high-resolution transducers (frequency dependent on the depth of the lesion) and color/power Doppler available. Extended field of view and compound imaging are desirable. If no mass is detected initially, frequency harmonic imaging for echo-poor solid masses may be useful. ${ }^{7}$

\section{Who Should Perform the Initial Ultrasound?}

Ideally, a board-certified radiologist (or, in the clinical setting, a radiologist with proven experience in sonographic soft tissue lesion assessment) should perform the US. We consider the radiologist (who also has access to other imaging modalities) the most suitable medical specialist for this issue. Purely cutaneous lesions can be assessed by a dermatologist, if specifically trained.

\section{What Should Be Described on Ultrasound?}

- Relation to the fascia (superficial, deep), exact anatomical location including compartmental involvement, the 
relationship to/infiltration of vessels/nerves, and, if possible, joints and/or bone and crucial adjacent structures.

- Size (in three dimensions).

- Morphology: cystic, solid (intralesional echo texture, vascularization, presence or absence of necrosis, bleeding, posterior acoustic enhancement/shadowing, suspected calcifications), shape, borders/margins.

\section{Criteria for Diagnosis of a Benign Lesion}

- Simple cyst, bursa, synovial/ganglion cyst: purely cystic well-defined lesion without any solid component, anechoic, with posterior acoustic enhancement and no internal vascularity. $^{8}$

- Superficial lipoma: homogeneous well defined, encapsulated, and compressible with no clinical concern and documented stability on US (at least 6 months follow-up). ${ }^{9,10}$

- Vascular malformation with no clinical concern and stability on US (at least 6 months follow-up). ${ }^{11}$

- Foreign body "granuloma" with a compatible history. ${ }^{12}$

- Superficial fibromatosis (e.g., palmar and plantar fibromatosis, infantile digit fibromatosis). ${ }^{13,14}$

- Muscle hernia. ${ }^{15}$

- Morton neuroma. ${ }^{16}$

- Peripheral nerve sheath tumors only in case of proven neurofibromatosis for the detection and monitoring of typical neurofibromas. If painful, additional investigations should be conducted. ${ }^{11,17}$

\section{Criteria for Follow-up by Ultrasound}

- Likely posttraumatic hematoma or follow-up of muscle tears (follow-up interval: depending on the size, 3-6 weeks).

- Follow-up or preoperative evaluation of soft tissue mass previously characterized by MRI, no surgery intended, or before surgery.

\section{Criteria for Proceeding to a Subsequent MRI}

- Any tumor with a reasonable chance of being malignant. ${ }^{18}$

- Location: below the superficial muscle fascia, or superficial, but obtuse contact with or crossing of the superficial fascia. ${ }^{19,20}$

- Size $>5 \mathrm{~cm}^{21}$

- Any clinical or sonographic doubt (i.e., cannot be positively diagnosed as benign)

- Tumor at the site of a previous excision, regardless of previous histology

- Any tumor that is not completely accessible by US

Primary MRI should be considered instead of US in the following indications:

- Clinical suspicion of malignancy: suspicious clinical examination (fixed lump, large mass), deep mass, persistent swelling after trauma, rapidly enlarging lesion (except small superficial lesions), osseous involvement, joint involvement.

- In every case of abdominal/ pelvic/ retroperitoneal/ paravertebral mass lesion detected incidentally with other imaging modalities (alternatively, a CT scan can be performed in these cases; see later).

Primary CT should be considered instead of US when the lesion is intrathoracic or intra-abdominal (including pelvic and retroperitoneal lesions). CT after US should be considered where there are contraindications to MRI (such as pacemakers) or when MRI is not available (for other CT indications, see later).

Projection radiography serves as a complementary imaging modality to show and characterize soft tissue calcification or ossification and bone involvement, ${ }^{22,23}$ particularly in deep palpable lesions, para-articular lesions, and large masses. For regions with a complex anatomy (e.g., axial skeleton, head/ neck, thoracic, and pelvic areas), CT is preferred over radiography.

\section{Further Imaging}

\section{MRI}

MRI is the imaging method with the best soft tissue contrast. It serves to further characterize the tumor and provide precise and reproducible local staging for therapy planning and selecting appropriate biopsy regions. ${ }^{24}$

MRI should preferably be performed in a sarcoma treatment center or by a radiologist with sufficient expertise in musculoskeletal radiology (MSK) (e.g., an ESSR diploma holder or a national MSK certification holder), with the potential to provide the electronic data set to a tumor center, if necessary.

\section{Technical MRI Requirements}

The field strength of the scanner should be at least $1 \mathrm{~T}$, but preferentially $1.5-\mathrm{T}$ or $3-\mathrm{T}$ units should be used. A cutaneous marker should be applied. The field of view should be as large as necessary to image the entire lesion, peritumoral edema, and a layer of adjacent normal tissue, ${ }^{25}$ and to image nonpalpable masses reliably (usually this aspect is especially important in coronal or sagittal sequences). Axial sequences with high spatial resolution are important to define tumor margins, tissue and compartment involvement, and neurovascular, bone, and joint involvement. The matrix should be optimized to achieve high in-plane spatial resolution, high signal-to-noise ratio, and a reasonable examination time (e.g., 256; if possible 384 , or [in T1-weighted, T2-weighted] even 512). The slice thickness should not exceed $4 \mathrm{~mm}$. In smaller tumors, 3-mm slices may be appropriate.

The tumor should be measured in three dimensions (sequences should be performed in at least two planes). At least one sequence should include an external bony landmark for measuring and operation planning. ${ }^{26}$

Recommended basic protocols include T1-weighted and a fluid-sensitive, fat-saturated (FS) sequence, both parallel to the long axis of the tumor. An axial T2-weighted sequence may provide further information about the tumor matrix. ${ }^{26-28}$ Some authors use only axial proton-density FS or T2 FS; one of these should be performed. We recommend using intravenous gadolinium-based contrast agents, if 
possible and feasible, at a routine dosage (usually, $0.1 \mathrm{mmol} /$ $\mathrm{kg}$ body weight). In patients with renal insufficiency, the European Society of Urogenital Radiology guidelines should be taken into account. ${ }^{29}$ Postcontrast sequences should be performed in two planes (routinely, the T1-weighted precontrast sequence along the long axis is repeated, and a FS T1weighted axial sequence is performed). Subtraction images (T1-weighted pre-subtracted from T1-weighted postcontrast) help identify truly enhancing tumor areas sensitively.

Additional sequences may include dynamic contrast enhancement and diffusion-weighted sequences that can be helpful in characterizing the tumor (especially vascularization and matrix) but are not currently mandatory. ${ }^{30-32}$ Pretreatment dynamic MR studies are useful as a baseline for follow-up MR scans to monitor response to chemotherapy.

\section{What Should Be Described on the MRI Report?}

- Lesion location and extension ${ }^{26}$

- Relation to the fascia (superficial, deep), exact anatomical location, with relationship to/infiltration of vessels/nerves, joints, and/or bone, muscles/compartments, ${ }^{33}$ and distance to external landmark.

- Size (in three dimensions)

Lesion morphology:

- Cystic, solid (matrix signal intensity, homogeneity, vascularity, enhancement, with and without necrosis, bleeding).

- Borders, lobularity, pseudocapsule, perifocal edema, and surrounding alterations

- Multiplicity and satellite lesions, abnormal proximal lymph nodes. ${ }^{26}$

\section{Criteria for a Determinate Lesion on MRI}

The following lesions may be reliably characterized on MRI: lipoma, ganglion cyst, Baker cyst, bursitis, vascular malformation, hematoma, myositis ossificans, peripheral nerve sheath tumor (neurofibromas/schwannomas), muscle tear, pigmented villonodular synovitis (PVNS), and aneurysm. ${ }^{34}$

If there is any doubt about tissue characterization, the patient should be referred to a sarcoma treatment center for a second opinion. ${ }^{35}$

\section{Referral to a Sarcoma Treatment Center}

Patients with soft tissue tumors should be referred regularly to a sarcoma treatment center for a primary or a secondary opinion. Soft tissue sarcomas should be managed by a multidisciplinary sarcoma team that includes an (orthopedic) tumor surgeon, musculoskeletal radiologist, oncologist, and musculoskeletal pathologist. Further members of the team would include radiotherapists, specialized physiotherapists, and so on.

Criteria for referral to a sarcoma treatment center:

- Any patient with a $\geq 5$-cm superficial tumor or with a deep-seated tumor regardless of size. ${ }^{36}$

- Indeterminate US or indeterminate MRI findings, or clinical suspicion of malignancy.

- Patients should be referred before biopsy or surgery.
Time intervals: The patient should ideally be reviewed by the sarcoma team and biopsied, if necessary, within 2 weeks.

\section{Criteria for Subsequent Biopsy}

A biopsy (usually image guided; for excisional or non-imageguided biopsy, see later) is indicated when the lesion is either indeterminate or if there is a likelihood of the lesion being malignant. In most cases, biopsy is necessary.

\section{Biopsy}

It is essential that the biopsy be performed in the sarcoma treatment center where the patient will receive further/ definitive treatment ${ }^{36}$ (with the future oncologic surgeon and a specialized pathologist involved). The decision to biopsy or not should be arrived at by a multidisciplinary approach including the oncologic surgeon.

\section{Biopsy Technique}

In most patients, the method of choice is closed imageguided biopsy. In tumors $\leq 3 \mathrm{~cm}$, particularly in superficial lesions, excisional biopsy may be appropriate. Rarely, for large and superficial lesions known to be homogeneous on recent imaging, non-image-guided biopsy may be appropriate.

Image-guided biopsy is minimally invasive, does not require general anesthesia or hospitalization, and has reasonable accuracy. ${ }^{37}$ Therefore, when the tumor is accessible, it is preferred over open biopsy (which is also appropriate).

Image-guided biopsy can be performed by US, MRI, or CT. US is recommended, especially in superficial, smaller, and homogeneous lesions. MRI or CT are especially preferred in thoracic, abdominal, or pelvic lesions. In practice, the choice depends on local expertise and the availability of imaging modalities.

It is essential to target viable tumor areas, identified by color Doppler US, ${ }^{38,39}$ contrast-enhanced MRI, ${ }^{40}$ or positron emission tomography (PET)/CT. ${ }^{41}$ Contrast-enhanced US $^{42}$ and dynamic contrast-enhanced $\mathrm{MRI}^{43}$ can help target representative areas.

The biopsy approach should be planned in collaboration with the sarcoma surgeon because the biopsy tract has to be removed en bloc at the time of surgery. Contamination of nonaffected compartments should be avoided. Core biopsy is appropriate. Fine-needle aspiration biopsy is inappropriate. ${ }^{44}$ We recommend a biopsy needle size of at least $14 \mathrm{G}$ (most appropriate), and taking more than three or four samples. ${ }^{28}$

Image-guided biopsy should be performed by a trained radiologist or the surgeon of the multidisciplinary tumor group in the sarcoma center after interdisciplinary discussion.

\section{Proven Sarcoma: Further Imaging}

In patients with histologically proven sarcoma, whole-body staging must be performed. When these results become available, further treatment should be planned by a multidisciplinary tumor board. 
Table 1 Whole-body staging in sarcoma

\begin{tabular}{|c|c|}
\hline $\begin{array}{l}\text { Chest CT scan (unenhanced) for } \\
\text { lung metastases }\end{array}$ & All soft tissue tumors \\
\hline PET scan for osseous metastases & $\begin{array}{l}\text { Alveolar soft part sarcoma } 47,48 \\
\text { Angiosarcoma } 47 \\
\text { Leiomyosarcoma } \\
\text { Undifferentiated pleomorphic sarcoma } \\
\text { Dedifferentiated liposarcoma } \\
\text { De }\end{array}$ \\
\hline Regional MRI/CT for lymph nodes & $\begin{array}{l}\text { Rhabdomyosarcoma, clear cell sarcomas, } \\
\text { epithelioid sarcoma, angiosarcoma, synovial sarcoma }\end{array}$ \\
\hline Abdominal CT & $\begin{array}{l}\text { Myxoid liposarcoma } \\
\text { Epithelioid sarcoma } \\
\text { Angiosarcoma } \\
\text { L4 } \\
\text { Leiomyosarcoma }^{55}\end{array}$ \\
\hline Brain imaging 58 & $\begin{array}{l}\text { Alveolar soft part sarcoma } \\
\text { Clear cell sarcoma, angiosarcoma } \\
\text { 54 }\end{array}$ \\
\hline MRI of the spine & Myxoid liposarcoma ${ }^{52}$ \\
\hline
\end{tabular}

Abbreviations: CT, computed tomography; MRI, magnetic resonance imaging; PET, positron emission tomography.

\section{Whole-Body Staging}

Staging should be performed according to the updated American Joint Committee on Cancer criteria $^{45}$ that includes histologic grading according to the French Federation of Cancer Centers (considering cell differentiation, mitotic count, and tumor necrosis).

Metastatic spread of soft tissue sarcomas mainly is hematogenous, and pulmonary metastases are most common, accounting for $\sim 75$ to $80 \%$ of metastases. CT of the chest (native three-dimensional volume helical CT with 1-mm reconstructions) is recommended. Other sites are less commonly involved. Osseous metastases occur in $\sim 10 \%$ of soft tissue sarcoma patients. ${ }^{46}$ Higher incidences have been described for alveolar soft part sarcomas, ${ }^{47,48}$ angiosarcomas, ${ }^{47}$ leiomyosarcomas, ${ }^{49}$ undifferentiated pleomorphic sarcomas, ${ }^{46}$ and dedifferentiated liposarcomas. ${ }^{47}$ Eighty percent of those osseous metastases are lytic, ${ }^{46}$ and fluorodeoxyglucose (FDG)-PET may be useful in these tumors.

Lymph node involvement is rare ( $\sim 3 \%$ of sarcomas) and is more frequent in high-grade rhabdomyosarcoma, clear cell sarcomas, epithelioid sarcoma, angiosarcoma, and synovial

Table 2 Example for follow-up intervals

\begin{tabular}{|l|l|}
\hline \multicolumn{2}{|l|}{$\begin{array}{l}\text { Clinical examination, local/regional MRI, and chest CT scan } \\
\text { (no contrast agent) }\end{array}$} \\
\hline Year after first treatment & Follow-up interval \\
\hline $1-3$ & $\begin{array}{l}\text { Grading-dependent, } \\
\text { every } 3-4 \text { mo }\end{array}$ \\
\hline $3-5$ & Every 6 mo \\
\hline$>5$, up to 10 & Annually \\
\hline $\begin{array}{l}\text { Consider tissue-specific additional modalities as detailed } \\
\text { in - Table } 1\end{array}$ \\
\hline
\end{tabular}

Abbreviations: CT, computed tomography; MRI, magnetic resonance imaging.

Adapted from Mazeron and Suit. ${ }^{50}$ sarcoma. ${ }^{50,51}$ Regional MRI/CT should be considered in those tumors.

In myxoid liposarcoma, ${ }^{52}$ epithelioid sarcoma, ${ }^{53}$ angiosarcoma, ${ }^{54}$ and leiomyosarcoma, ${ }^{55}$ abdominal CT should be considered. In alveolar soft part sarcoma with lung metastases, ${ }^{56,57}$ in clear cell sarcoma, and angiosarcoma, ${ }^{54}$ brain imaging should be considered. ${ }^{58}$ In myxoid liposarcoma, ${ }^{52}$ MRI of the spine should be considered.

The role of PET/CT and PET/MR for initial staging, therapy control, and follow-up is still regarded as controversial. It may lead to upstaging in only a minority of patients and is currently not recommended for routine use. ${ }^{59}$

\section{Follow-Up}

To date, there are no evidence-based recommendations for routine follow-up in surgically treated sarcomas. In several European countries, follow-up is performed regularly for 10 years after the initial diagnosis.

Generally, a baseline examination 3 to 6 months postoperatively, followed by 3- to 6-month intervals up to the fifth year, and 12 months thereafter, are recommended in the American College of Radiology (ACR) appropriateness criteria. ${ }^{60}$ The recurrence rate is known to be influenced by the tumor grade. ${ }^{61}$ As proposed by the European Society of Medical Oncology (ESMO) and national societies, we recommend follow-up intervals that depend on tumor grade: for intermediate or high-grade sarcomas, intervals of 3 to 4 months in the first 2 to 3 years, and, in low-grade sarcomas, 4 to 6 months in the first 3 years; subsequently for both, 6month intervals up to the fifth year. ${ }^{62-64}$ We also recommend 12-month intervals from the fifth to tenth years. In case of symptoms/suspected recurrence, follow-up can be performed earlier.

Apart from clinical and laboratory examinations, followup includes imaging for local recurrence and metastatic disease. There is debate about whether imaging should be 
Table 3 Key points

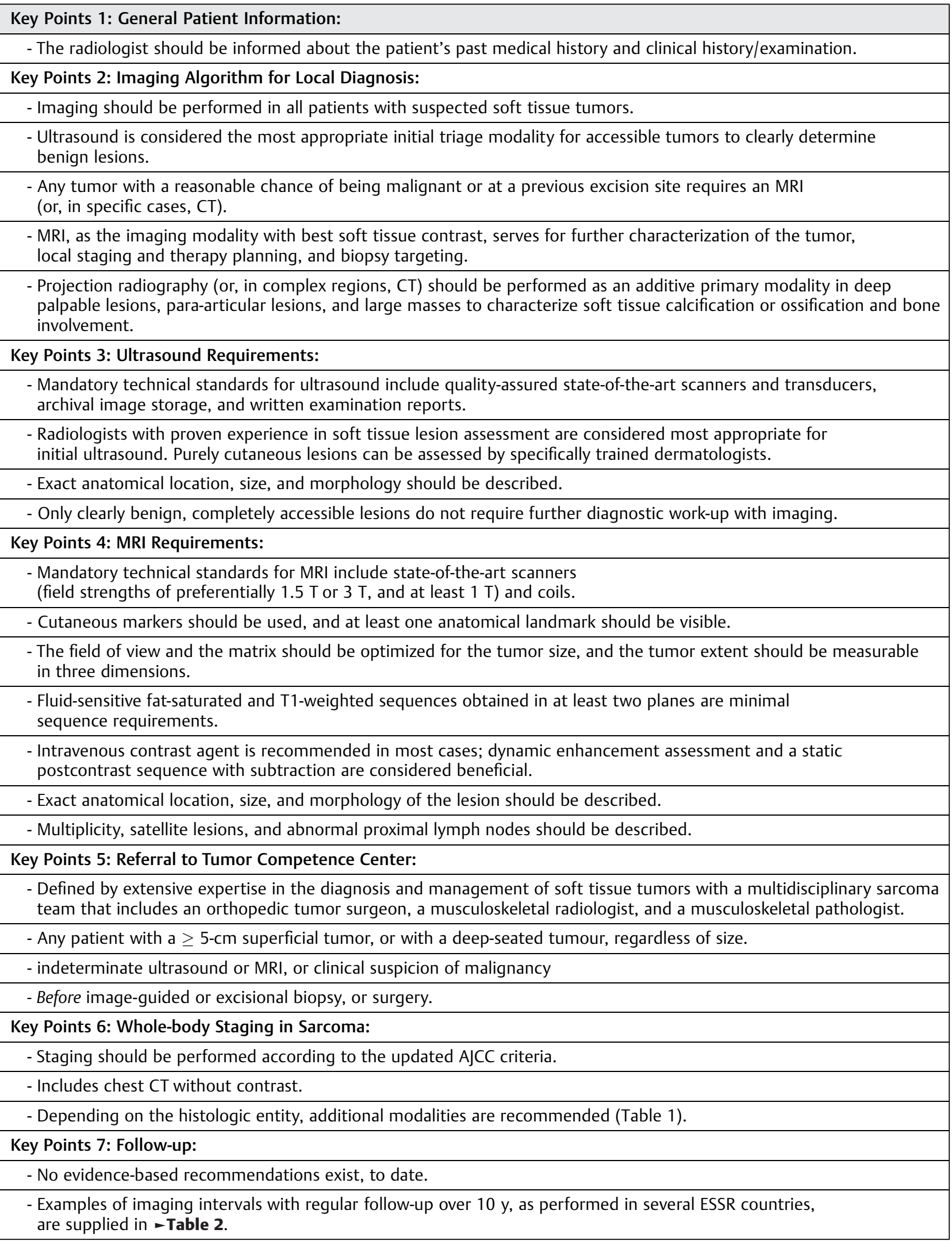

Abbreviations: AJCC, American Joint Committee on Cancer; CT, computed tomography; ESSR, European Society of Musculoskeletal Radiology. 
performed regularly ${ }^{18,60}$ or only in symptomatic cases. ${ }^{62}$ However, local recurrences are, especially in retroperitoneal lesions, desmoid type fibromatosis, and lesions with marked surrounding scar tissue, initially not palpable. We therefore recommend regular imaging. - Table 2.

In limb sarcomas, US seems promising for exclusion of local recurrence. ${ }^{65}$ To date, local MRI (including contrastenhanced sequences) is considered the method of choice for local surveillance. ${ }^{24,66}$

The follow-up MRI should be compared with the preoperative MRI (for morphology, site, and extent of the lesion). The MR protocol should include at least a fluid-sensitive, fatsaturated sequence (long and short axis), a T1-weighted sequence without contrast agent, and, in case of a focal mass, a T1-weighted sequence with contrast agent (with subtraction). ${ }^{67}$ A T2-weighted sequence may add to lesion morphology assessment and thus should be included in the protocol. If available and feasible, a delayed contrast enhancement and diffusion-weighted imaging sequence may be performed. ${ }^{67,68}$

In case of metallic hardware, lower field strengths are preferred, and dedicated sequences that are optimized for minimizing susceptibility artifacts should be used. In case of large metallic hardware, US, dual-energy CT or CT using modern iterative reconstruction algorithms of raw data sets, or PET/CT can be considered as alternative or additive to MRI.

Chest CT (without contrast, helical three-dimensional volume acquisition with $1-\mathrm{mm}$ reconstructions) is recommended for lung metastasis surveillance in accordance with ACR criteria ${ }^{60}$ because it is more sensitive than projection radiography.

\section{Acknowledgments}

We thank J. Panotopoulos and T. Brodowicz for their advice on clinical issues, and P. Szomolanyi for his help in preparing the manuscript.

Notes

Approved by the ESSR MSK Tumour Subcommittee.

\section{References}

1 Fletcher CDM, Bridge JA, Hogendoorn P, Mertens F. WHO Classification of Tumours of Soft Tissue and Bone. 4th ed. Lyon, France: IARC Press; 2013

2 National Cancer Institute. SEER Stat Fact Sheets: Soft tissue including heart cancer. Available at: http://seer.cancer.gov/statfacts/html/soft.html. Accessed December 7, 2015

3 Nakamura T, Matsumine A, Matsubara T, Asanuma K, Uchida A, Sudo A. The symptom-to-diagnosis delay in soft tissue sarcoma influence the overall survival and the development of distant metastasis. J Surg Oncol 2011;104(7):771-775

4 Lakkaraju A, Sinha R, Garikipati R, Edward S, Robinson P. Ultrasound for initial evaluation and triage of clinically suspicious softtissue masses. Clin Radiol 2009;64(6):615-621
5 Rowbotham E, Bhuva S, Gupta H, Robinson P. Assessment of referrals into the soft tissue sarcoma service: evaluation of imaging early in the pathway process. Sarcoma 2012;2012:781723

6 Ritchie DA. Commentary on ultrasound for initial evaluation and triage of clinically suspicious soft-tissue masses. Clin Radiol 2009; 64(6):622-623

7 Campbell R. Ultrasound of soft tissue masses. In: Allan PL, Baxter GM, Weston MJ eds. Clinical Ultrasound. 3rd ed. Philadelphia, PA: Churchill Livingstone/Elsevier; 2011

8 Klauser AS, Tagliafico A, Allen GM, et al. Clinical indications for musculoskeletal ultrasound: a Delphi-based consensus paper of the European Society of Musculoskeletal Radiology. Eur Radiol 2012;22(5):1140-1148

9 Inampudi P, Jacobson JA, Fessell DP, et al. Soft-tissue lipomas: accuracy of sonography in diagnosis with pathologic correlation. Radiology 2004;233(3):763-767

10 Wagner JM, Lee KS, Rosas H, Kliewer MA. Accuracy of sonographic diagnosis of superficial masses. J Ultrasound Med 2013;32(8): 1443-1450

11 Carra BJ, Bui-Mansfield LT, O'Brien SD, Chen DC. Sonography of musculoskeletal soft-tissue masses: techniques, pearls, and pitfalls. AJR Am J Roentgenol 2014;202(6):1281-1290

12 Horton LK, Jacobson JA, Powell A, Fessell DP, Hayes CW. Sonography and radiography of soft-tissue foreign bodies. AJR Am J Roentgenol 2001;176(5):1155-1159

13 Griffith JF, Wong TY, Wong SM, Wong MW, Metreweli C. Sonography of plantar fibromatosis. AJR Am J Roentgenol 2002;179(5): 1167-1172

14 Vanhoenacker FM, Eyselbergs M, Van Hul E, Van Dyck P, De Schepper AM. Pseudotumoural soft tissue lesions of the hand and wrist: a pictorial review. Insights Imaging 2011;2(3):319-333

15 Beggs I. Sonography of muscle hernias. AJR Am J Roentgenol 2003; 180(2):395-399

16 Quinn TJ, Jacobson JA, Craig JG, van Holsbeeck MT. Sonography of Morton's neuromas. AJR Am J Roentgenol 2000;174(6):1723-1728

17 Reynolds DL Jr, Jacobson JA, Inampudi P, Jamadar DA, Ebrahim FS, Hayes CW. Sonographic characteristics of peripheral nerve sheath tumors. AJR Am J Roentgenol 2004;182(3):741-744

18 National Comprehensive Cancer Network. NCCN Clinical Practice Guidelines in Oncology. Available at: http://www.nccn.org/professionals/physician_gls/f_guidelines_nojava.asp. Accessed December 11,2015

19 Galant J, Martí-Bonmatí L, Soler R, et al. Grading of subcutaneous soft tissue tumors by means of their relationship with the superficial fascia on MR imaging. Skeletal Radiol 1998;27(12):657-663

20 Morel M, Taïeb S, Penel N, et al. Imaging of the most frequent superficial soft-tissue sarcomas. Skeletal Radiol 2011;40(3): 271-284

21 Datir A, James SL, Ali K, Lee J, Ahmad M, Saifuddin A. MRI of softtissue masses: the relationship between lesion size, depth, and diagnosis. Clin Radiol 2008;63(4):373-378; discussion 379-380

22 Gartner L, Pearce CJ, Saifuddin A. The role of the plain radiograph in the characterisation of soft tissue tumours. Skeletal Radiol 2009;38(6):549-558

23 De Schepper AM, Vanhoenacker F, Parizel PM, Gielen J eds. Imaging of Soft Tissue Tumors. Berlin, Germany: Springer-Verlag; 2006

24 Verstraete KL, Lang P. Bone and soft tissue tumors: the role of contrast agents for MR imaging. Eur J Radiol 2000;34(3):229-246

25 White LM, Wunder JS, Bell RS, et al. Histologic assessment of peritumoral edema in soft tissue sarcoma. Int J Radiat Oncol Biol Phys 2005;61(5):1439-1445

26 Manaster BJ. Soft-tissue masses: optimal imaging protocol and reporting. AJR Am J Roentgenol 2013;201(3):505-514

27 Dinauer PA, Brixey CJ, Moncur JT, Fanburg-Smith JC, Murphey MD. Pathologic and MR imaging features of benign fibrous soft-tissue tumors in adults. Radiographics 2007;27(1):173-187 
28 Wu JS, Hochman MG. Soft-tissue tumors and tumorlike lesions: a systematic imaging approach. Radiology 2009;253(2):297-316

29 European Society of Urogenital Radiology (ESUR) Guidelines on Contrast Media. Available from: http://www.esur.org/guidelines/. Accessed December 11, 2015

30 van Rijswijk CS, Geirnaerdt MJ, Hogendoorn PC, et al. Soft-tissue tumors: value of static and dynamic gadopentetate dimeglumineenhanced MR imaging in prediction of malignancy. Radiology 2004;233(2):493-502

31 van Rijswijk CS, Kunz P, Hogendoorn PC, Taminiau AH, Doornbos J, Bloem JL. Diffusion-weighted MRI in the characterization of softtissue tumors. J Magn Reson Imaging 2002;15(3):302-307

32 Subhawong TK, Jacobs MA, Fayad LM. Diffusion-weighted MR imaging for characterizing musculoskeletal lesions. Radiographics 2014;34(5):1163-1177

33 Holzapfel K, Regler J, Baum T, et al. Local staging of soft-tissue sarcoma: emphasis on assessment of neurovascular encasementvalue of MR imaging in 174 confirmed cases. Radiology 2015; 275(2):501-509

34 Papp DF, Khanna AJ, McCarthy EF, Carrino JA, Farber AJ, Frassica FJ. Magnetic resonance imaging of soft-tissue tumors: determinate and indeterminate lesions. J Bone Joint Surg Am 2007;89 (Suppl 3):103-115

35 Vanhoenacker FM, Van Looveren K, Trap K, et al. Grading and characterization of soft tissue tumors on magnetic resonance imaging: the value of an expert second opinion report. Insights Imaging 2012;3(2):131-138

36 Styring E, Billing V, Hartman L, et al. Simple guidelines for efficient referral of soft-tissue sarcomas: a population-based evaluation of adherence to guidelines and referral patterns. J Bone Joint Surg Am 2012;94(14):1291-1296

37 Yang J, Frassica FJ, Fayad L, Clark DP, Weber KL. Analysis of nondiagnostic results after image-guided needle biopsies of musculoskeletal lesions. Clin Orthop Relat Res 2010;468(11):3103-3111

38 Peer S, Freuis T, Loizides A, Gruber H. Ultrasound guided core needle biopsy of soft tissue tumors; a fool proof technique? Med Ultrasound 2011;13(3):187-194

39 Pohlig F, Kirchhoff C, Lenze U, et al. Percutaneous core needle biopsy versus open biopsy in diagnostics of bone and soft tissue sarcoma: a retrospective study. Eur J Med Res 2012;17:29

40 Koenig CW, Duda SH, Truebenbach J, et al. MR-guided biopsy of musculoskeletal lesions in a low-field system. J Magn Reson Imaging 2001;13(5):761-768

41 Purandare NC, Kulkarni AV, Kulkarni SS, et al. 18F-FDG PET/CTdirected biopsy: does it offer incremental benefit? Nucl Med Commun 2013;34(3):203-210

42 De Marchi A, Brach del Prever EM, Linari A, et al. Accuracy of coreneedle biopsy after contrast-enhanced ultrasound in soft-tissue tumours. Eur Radiol 2010;20(11):2740-2748

43 Noebauer-Huhmann IM, Amann G, Krssak M, et al. Use of diagnostic dynamic contrast-enhanced (DCE)-MRI for targeting of soft tissue tumour biopsies at 3T: preliminary results. Eur Radiol 2015; 25(7):2041-2048

44 Yang YJ, Damron TA. Comparison of needle core biopsy and fineneedle aspiration for diagnostic accuracy in musculoskeletal lesions. Arch Pathol Lab Med 2004;128(7):759-764

45 American Joint Committee on Cancer. How are soft tissue sarcomas staged? Available from: http://www.cancer.org/cancer/sarcoma-adultsofttissuecancer/detailedguide/sarcoma-adult-softtissue-cancer-staging. Accessed December 11, 2015

46 Vincenzi B, Frezza AM, Schiavon G, et al. Bone metastases in soft tissue sarcoma: a survey of natural history, prognostic value and treatment options. Clin Sarcoma Res 2013;3(1):6

47 Yoshikawa H, Myoui A, Ochi T, et al. Bone metastases from soft tissue sarcomas. Semin Musculoskelet Radiol 1999;3(2):183-190

48 Sood $S$, Baheti $A D$, Shinagare $A B$, et al. Imaging features of primary and metastatic alveolar soft part sarcoma: single institute experience in 25 patients. $\mathrm{Br} \mathrm{J}$ Radiol 2014; 87(1036):20130719

49 Gordon RW, Tirumani SH, Kurra V, et al. MRI, MDCT features, and clinical outcome of extremity leiomyosarcomas: experience in 47 patients. Skeletal Radiol 2014;43(5):615-622

50 Mazeron II, Suit HD. Lymph nodes as sites of metastases from sarcomas of soft tissue. Cancer 1987;60(8):1800-1808

51 Sherman KL, Kinnier CV, Farina DA, et al. Examination of national lymph node evaluation practices for adult extremity soft tissue sarcoma. J Surg Oncol 2014;110(6):682-688

52 Haniball J, Sumathi VP, Kindblom LG, et al. Prognostic factors and metastatic patterns in primary myxoid/round-cell liposarcoma. Sarcoma 2011;2011:538085

53 Chase DR, Enzinger FM. Epithelioid sarcoma. Diagnosis, prognostic indicators, and treatment. Am J Surg Pathol 1985;9(4): 241-263

54 Meis-Kindblom JM, Kindblom LG. Angiosarcoma of soft tissue: a study of 80 cases. Am J Surg Pathol 1998;22(6):683-697

55 Mankin HJ, Casas-Ganem J, Kim JI, Gebhardt MC, Hornicek FJ, Zeegen EN. Leiomyosarcoma of somatic soft tissues. Clin Orthop Relat Res 2004;(421):225-231

56 Lieberman PH, Brennan MF, Kimmel M, Erlandson RA, Garin-Chesa P, Flehinger BY. Alveolar soft-part sarcoma. A clinico-pathologic study of half a century. Cancer 1989;63(1):1-13

57 Portera CA Jr, Ho V, Patel SR, et al. Alveolar soft part sarcoma: clinical course and patterns of metastasis in 70 patients treated at a single institution. Cancer 2001;91(3):585-591

58 Espat NJ, Bilsky M, Lewis JJ, Leung D, Brennan MF. Soft tissue sarcoma brain metastases. Prevalence in a cohort of 3829 patients. Cancer 2002;94(10):2706-2711

59 Roberge D, Vakilian S, Alabed YZ, Turcotte RE, Freeman CR, Hickeson M. FDG PET/CT in initial staging of adult soft-tissue sarcoma. Sarcoma 2012;2012:960194

60 National Guideline Clearinghouse. ACR Appropriateness Criteria ${ }^{\circledR}$ follow-up of malignant or aggressive musculoskeletal tumors. Available at: https://acsearch.acr.org/docs/69428/Narrative/. Accessed December 7, 2015

61 Grobmyer SR, Brennan MF. Predictive variables detailing the recurrence rate of soft tissue sarcomas. Curr Opin Oncol 2003; 15(4):319-326

62 Cancer Research UK. Follow up for soft tissue sarcoma. Available from: http://www.cancerresearchuk.org/about-cancer/type/ sarcoma/treatment/follow-up-for-soft-tissue-sarcoma. Accessed December 11, 2015

63 AMSOS. Austrian Musculoskeletal Oncology Society. Available at: http://www.amsos.at. Accessed December 7, 2015

64 ESMO/European Sarcoma Network Working Group. Soft tissue and visceral sarcomas: ESMO Clinical Practice Guidelines for diagnosis, treatment and follow-up. Ann Oncol 2014;25(Suppl 3): iii102-iii112

65 Tagliafico A, Truini M, Spina B, et al. Follow-up of recurrences of limb soft tissue sarcomas in patients with localized disease: performance of ultrasound. Eur Radiol 2015;25(9): 2764-2770

66 Diana Afonso P, Kosinski AS, Spritzer CE. Following unenhanced MRI assessment for local recurrence after surgical resection of mesenchymal soft tissue tumors, do additional gadolinium-enhanced images change reader confidence or diagnosis? Eur J Radiol 2013;82(5):806-813

67 Vanel D, Shapeero LG, Tardivon A, Western A, Guinebretière JM. Dynamic contrast-enhanced MRI with subtraction of aggressive soft tissue tumors after resection. Skeletal Radiol 1998;27(9): 505-510

68 Del Grande F, Subhawong T, Weber K, Aro M, Mugera C, Fayad LM. Detection of soft-tissue sarcoma recurrence: added value of functional MR imaging techniques at 3.0 T. Radiology 2014; 271(2):499-511 